Int. J. Electrochem. Sci., 14 (2019) 11480 - 11490

International Journal of

ELECTROCHEMICAL

SCIENCE

$\underline{\text { WwW.electrochemsci.org }}$

\title{
Triblock Copolymer Pluronic F68 as a Corrosion Inhibitor for Aluminum-air Battery: An Electrochemical and in Silico Study
}

\author{
Lei Guo ${ }^{1, *}$, Jianhong Tan ${ }^{2}$, Hong Yang ${ }^{1}$, Youness El Bakri ${ }^{3,4}$, Savaş Kaya ${ }^{5}$, Senlin Leng ${ }^{1}$, Yingchang \\ Yang $^{1}$, Wei Shi ${ }^{1}$ \\ ${ }^{1}$ School of Material and Chemical Engieering, Tongren University, Tongren 554300, China \\ ${ }^{2}$ School of Chemistry and Chemical Engineering, Yangtze Normal University, Chongqing 408100, \\ China \\ ${ }^{3}$ Laboratoire de Chimie Organique Hétérocyclique, Centre de Recherche des Sciences des \\ Médicaments, Pôle de Compétences Pharmacochimie, URAC 21, Faculté des Sciences, Mohammed V \\ University Rabat, Avenue Ibn Battouta, BP 1014, Rabat, Morocco \\ ${ }^{4}$ Department of Organic Chemistry, Science Faculty, RUDN University Miklukho-Maklayast.6, \\ Moscow 117198, Russian Federation \\ ${ }^{5}$ Department of Chemistry, Faculty of Science, Cumhuriyet University, Sivas 58140, Turkey
}

*E-mail: cqglei@163.com

doi: $10.20964 / 2019.12 .19$

Received: 9 July 2019 / Accepted: 6 September 2019 / Published: 29 October 2019

In Al-air batteries, the self-corrosion of aluminum electrodes is an issue worthy of concern. In this paper, the inhibition performance and anti-corrosion mechanism of a triblock copolymer, namely, Pluronic F68, on $\mathrm{Al}$ in $3.5 \% \mathrm{NaCl}$ electrolyte are investigated with a multidimension approach combining electrochemical and theoretical approaches. The results suggest that Pluronic F68 inhibitor can present wonderful anticorrosion efficiency, and the maximum inhibition efficiency can reach $94 \%$ at low dose concentration. Meanwhile, the battery containing Pluronic F68 exhibits better performance. Significantly, the present work is beneficial to understand the inhibition mechanism of similar organic polymers and provides a feasible approach to develop Al-air batteries.

Keywords: Al-air battery, Corrosion inhibition, Electrochemistry; Theoretical calculations

\section{$\underline{\text { FULL TEXT }}$}

(C) 2019 The Authors. Published by ESG (www.electrochemsci.org). This article is an open access article distributed under the terms and conditions of the Creative Commons Attribution license (http://creativecommons.org/licenses/by/4.0/). 